\title{
O IMPACTO DA INOVAÇÃO NO DESEMPENHO ECONÔMICO-FINANCEIRO DAS MPEIS CATARINENSES BENEFICIADAS PELO PROGRAMA JURO ZERO
} (FINEP)

\section{THE IMPACT OF THE INNOVATION IN THE ECONOMIC-FINANCIAL PERFORMANCE OF SANTA CATARINA'S IMSES BENEFITED BY ZERO}

\author{
ALESSANDRA VASCONCELOS GALLON \\ Doutora em Engenharia de Produção pela Universidade Federal de Santa \\ Catarina, UFSC, Brasil.
Professora da Universidade Federal do Ceará, UFC \\ Fortaleza, CE - Brasil
E-mail: alegallon@terra.com.br \\ DIANE ROSSI MAXIMIANO REINA \\ Mestre em andamento em Contabilidade pela Universidade Federal de Santa Catarina \\ Professora do Instituto de Ensino Superior da Grande Florianopólis, IES \\ Florianopolis, SC - Brasil. \\ E-mail: dianereina@hotmail.com \\ SANDRA ROLIM ENSSLIN
em Engenharia de Producão Universidade Federal de Santa Catarina \\ Doutora em Engenharia de Produção Universidade Federal de Santa C C
Professora da Universidade Federal de Santa Catarina, UFSC \\ Florianopolis, SC - Brasil.
E-mail: sensslin@gmail
}

\section{Resumo}

Inovação é considerada, a partir dos anos 90 , um tema estratégico para o desenvolvimento das Micro e Pequenas Empresas. Embora apontada como um fator crítico para a obtenção de vantagem competitiva, muito ainda há que ser desenvolvido para fomentá-la e descobrir suas variáveis incentivadoras. Nesse contexto, esta pesquisa de natureza descritiva, realizada por meio de um estudo de casos múltiplos, com abordagem qualitativa-quantitativa dos dados, busca analisar o impacto do projeto inovador financiado pelo Programa Juro Zero (PJZ) da FINEP no desempenho econômico-financeiro das MPEls catarinenses. Em linhas gerais, os resultados evidenciaram que $22,73 \%$ das MPEls catarinenses efetuaram o registro de marca e patente do produto financiado pelo PJZ, e que a maioria das empresas firmaram parcerias e/ ou cooperações com instituições de pesquisa para a execução do projeto inovador, fatos esses que confirmam a geração da inovação e de capacidade tecnológica nas empresas. Com relação ao desempenho econômico-financeiro, houve uma evolução no faturamento médio e também uma melhora nos índices de liquidez e rentabilidade das MPEls no período pós-financiamento. Por fim, concluiu-se que o PJZ tem atingido seu objetivo por meio da promoção da capacidade inovadora e consequentemente contribuiu para a sustentabilidade das MPEls catarinenses analisadas.

Palavras-chave: Inovação. Desempenho econômico-financeiro. Micro e pequenas empresas inovadoras (MPEls) catarinenses.

\section{Abstract}

Innovation is considered, from years 90 , a strategical subject for the development of the Micron and Small Enterprises. Although pointed as a critical factor with respect to the attainment of competitive advantage, there is much to be developed in order to foment it and to discover its stimulative variables. In this context, this research of descriptive nature, carried through by means of multiple cases study, with qualitative-quantitative approach of the data, searchs to analyze the impact of the innovative project financed by Zero Interest Program of FINEP in the economic-financial performance of Santa Catarina's IMSEs [Innovative Micro and Small Enterprises]. In general lines, the results had evidenced tha $22.73 \%$ of Santa Catarina's IMSEs had registered their trademark and patent of the product financed by the 'Zero Interest Program', and that the majority of the companies had firmed partnerships and/ or cooperation with research institutions for the execution of the innovative project, facts that confirm the generation of the innovation and technological capacity in the companies. Regarding the economic-financial performance, there has been an evolution in the average invoicing and an improvement in the liquidify ratios and yield of the IMSEs in the period after-financincig. Finally, one concluded that the Zero Interest Program has reached its objective by means of the promotion of the innovative capacity and consequentently it contributed for the support of the analyzed Santa Catarina's IMSES.

Keywords: Innovation. Economic-financial performance. Innovative Micro and Small Enterprises. 


\section{INTRODUÇÃO}

No Brasil, o fechamento prematuro de empresas tem sido uma das preocupações da sociedade, particularmente para as entidades que desenvolvem programas de apoio ao segmento de pequeno porte.

Conforme os dados obtidos na pesquisa realizada pelo Serviço Brasileiro de Apoio às Micro e Pequenas Empresas (SEBRAE), em 2004, estima-se que 49,4\% das Micro e Pequenas Empresas (MPEs) brasileiras desaparecem antes do segundo ano de existência. Esse percentual se eleva para $56,4 \%$ para empresas com até três anos de existência, e 59,9\% para empresas com até quatro anos de existência (SEBRAE, 2004). Segundo Pascotto e Machado (2006, p.59), "a realidade de recursos internos na pequena empresa geralmente se apresenta como forte restrição à sua gestão", situação que pode ser um dos aspectos que justificam o fechamento prematuro das MPEs.

Em Micro e Pequenas Empresas Inovadoras (MPEls), esse insucesso pode ser, adicionalmente, explicado por fatores tais como: (i) alto grau de investimento em tecnologia, frequentemente maior do que em empresas tradicionais, gerando riscos mais altos; (ii) dificuldades em transformar uma tecnologia em uma empresa, uma vez que uma inovação, por si só não é suficiente para criar ou manter uma empresa; (iii) capacidade gerencial deficiente por parte dos empreendedores tecnológicos, que normalmente concentram conhecimentos e habilidades técnicas, que geram inovações (MARTINEZ, 2003); e, (iv) dificuldade de as MPEls criarem um mercado para os produtos inovadores que oferecem (BAÊTA; BORGES; TREMBLAY, 2006).

Em função dos altos custos e riscos característicos da inovação tecnológica, no Brasil, boa parte dos recursos destinados aos investimentos iniciais em Empresas Emergentes e de Base Tecnológica (EBTs) tem sido obtida junto a fontes de recursos governamentais, o que mostra a importância do setor público e o rumo das políticas públicas para fazer frente e incentivar empreendimentos dessa natureza (CORDER; SALLES-FILHO, 2006).

Nessa perspectiva, com o intuito de apoiar projetos desenvolvidos por MPEls, que representem uma inovação em seu setor de atuação, seja nos aspectos comerciais, gerenciais, de processos ou de produtos e/ou serviços, a Financiadora de Estudos e Projetos (FINEP), empresa pública vinculada ao MCT, lançou em 2006 o Programa Juro Zero (PJZ). A principal finalidade desse Programa é estimular o desenvolvimento das MPEls brasileiras viabilizando o acesso ao crédito por meio de financiamentos de longo prazo, com juro real igual a zero e sem a necessidade de apresentação de garantias reais. A primeira fase do PJZ entrou em operação no mesmo ano com atuação nos estados de Pernambuco, Minas Gerais, Paraná, Bahia e Santa Catarina (estado escopo da pesquisa).

Diante de tal contexto, emerge a seguinte pergunta de pesquisa que informa este estudo: qual o impacto do Programa Juro Zero da FINEP no desempenho econômico-financeiro das MPEls catarinenses? Para tal questionamento o presente artigo tem como objetivo principal: analisar o impacto do projeto inovador 
financiado pelo Programa Juro Zero (PJZ) da FINEP no desempenho econômicofinanceiro das MPEls catarinenses. Na busca de resposta ao problema central da pesquisa, foram formulados os seguintes objetivos específicos: (i) traçar o perfil das MPEls catarinenses beneficiadas pelo PJZ; (ii) descrever as particularidades dos projetos inovadores catarinenses financiados pelo PJZ; (iii) identificar aspectos da inovação desenvolvida nas MPEls catarinenses beneficiadas pelo PJZ; e, (iv) analisar as alterações no desempenho econômico-financeiro das MPEls com a implementação do projeto inovador financiado pelo PJZ.

Segundo Gitman (2002, p. 100), “a análise das demonstrações financeiras fornece um ponto inicial para se compreender uma empresa". Por esse ponto de vista, pode-se dizer que a análise econômico-financeira é um meio de se obter a real situação da empresa. Nesse sentido, a relevância da pesquisa justifica-se por analisar e apresentar o impacto do PJZ no desempenho econômico-financeiro das MPEls evidenciando sua contribuição para a sustentabilidade dessas empresas, que tanto contribuem para o desenvolvimento econômico de nosso País.

\section{PLATAFORMA TEÓRICA}

\subsection{IMPORTÂNCIA DAS FONTES DE RECURSOS GOVERNAMENTAIS PARA INCENTIVO À INOVAÇÃO TECNOLÓGICA EM MPEIS}

Os três eixos teóricos que informam o presente estudo são explorados, em termos de revisão de literatura, nas subseções a seguir.

De acordo com Alvim (1998, p. 31), “as empresas de pequeno porte no Brasil são responsáveis por: cerca de quatro milhões de empresas constituídas; $60 \%$ da oferta total de empregos formais; $42 \%$ dos salários pagos; $21 \%$ da participação no PIB; e 96,3\% do número de estabelecimentos". Diante disso, o autor afirma que "a competitividade das pequenas empresas brasileiras é essencial ao desenvolvimento do país" (ALVIM, 1998, p. 31).

Para tanto, conforme Corder e Salles-Filho (2006), como forma de auxílio à inovação tecnológica, as MPEls brasileiras buscam entre as entidades governamentais recursos oriundos de subvenção ou financiamentos para desenvolvimento das atividades inovadoras. Na mesma linha de raciocínio, a Organization for Economic Cooperation and Development (OECD, 2009) declara que apenas 10\% das pequenas EBTs realizam pesquisas com recursos próprios, enquanto as demais se utilizam de recursos do governo e de institutos de pesquisa.

Nesse sentido, como forma de auxílio às MPEls catarinenses (recorte da pesquisa), algumas entidades governamentais têm aberto editais ou chamadas públicas com esse propósito no Estado de Santa Catarina. A seguir, apresentam-se alguns editais de subvenção econômica (recursos não reembolsáveis) que beneficiaram empresas de tecnologia catarinenses em 2008 e 2009. Segundo informações da FINEP (2009), o marco-regulatório que viabiliza a concessão de subvenção econômica foi estabelecido com a aprovação da Lei $n^{\circ} 10.973 / 2004$, regulamentada pelo Decreto $n^{\circ}$ 
5.563/2005 (denominada Lei da Inovação), e da Lei n ${ }^{\circ} 11.196 / 2005$, regulamentada pelo Decreto n. 5.798/2006 (denominada Lei do Bem) - novo cenário vocacionado para a promoção da inovação nas empresas no País.

O primeiro programa a ser destacado é o Programa de Subvenção Econômica à Inovação em Micro e Pequenas Empresas de Santa Catarina (PAPPE - Subvenção/ $\mathrm{SC})$, lançado nos termos do Convênio firmado entre FINEP/MCT, Fundação de Apoio à Pesquisa Científica e Tecnológica do Estado de Santa Catarina (FAPESC) e SEBRAE/SC. Esse Programa visa selecionar propostas voltadas à pesquisa e ao desenvolvimento de processos e produtos inovadores em MPEs catarinenses, com o intuito de: (i) estimular seu desenvolvimento; (ii) aumentar sua competitividade; (iii) contribuir para o desenvolvimento tecnológico regional; e, (iv) contribuir para a geração e manutenção de emprego e renda na região. Para atingir o objetivo, foram disponibilizados recursos não reembolsáveis no valor de $\mathrm{R} \$ 9,5$ milhões. No ano de 2008, por meio desse Programa, foram beneficiadas 37 empresas no Estado, sendo que a maior parte dos recursos (61\%) foi alocada entre empresas estabelecidas na Grande Florianópolis (polo de tecnologia reconhecido nacionalmente), seguido das empresas localizadas no Alto Vale do Itajaí (Blumenau e Agrolândia). O valor da subvenção concedido por empresa oscilou entre $\mathrm{R} \$ 55.930,00$ e R\$ 300.000,00 (valor máximo concedido pelo Programa), de acordo com o atendimento pela empresa dos critérios estabelecidos no respectivo edital.

Outro programa que beneficiou as empresas de tecnologia catarinenses é o Programa de Capacitação de Recursos Humanos para Atividades Estratégicas (RHAE), do Conselho Nacional de Desenvolvimento Científico e Tecnológico (CNPq/MCT), de concessão de subvenção econômica por meio de bolsas para desenvolvimento científico e/ou tecnológico. Esse Programa nacional tem por objetivo estimular a inserção de mestres e doutores nas empresas para desenvolverem atividades de pesquisa científica, tecnológica e de inovação, atendendo aos objetivos do Plano de ação de ciência, tecnologia e inovação para o desenvolvimento nacional. Em todo o País, as propostas aprovadas foram financiadas pelo CNPq com recursos no valor global estimado em R\$ 26 milhões, tendo os projetos aprovados de cada empresa o valor máximo de R\$ 300 mil. Em 2008, foram beneficiadas nove empresas catarinenses por meio desse programa de subvenção, sendo que dessas $67 \%$ estão estabelecidas em Florianópolis.

Por fim, destaca-se o Programa de Subvenção Econômica à Inovação da FINEP/MCT que tem por objetivo apoiar o desenvolvimento de produtos, serviços e processos inovadores em empresas brasileiras por meio de subvenção econômica. Foram apoiados projetos de inovação até o limite total de R\$ 450 milhões dentro das seguintes áreas: tecnologias da informação e comunicação, biotecnologia, saúde, programas estratégicos, energia e desenvolvimento social. Para esse Programa foram abertos editais em 2008 e em 2009. Em 2008, foram beneficiadas 17 empresas catarinenses, totalizando um montante de aproximadamente R\$ 26 milhões, e, em 2009, foram beneficiadas 12 empresas, com aproximadamente R\$17 milhões. A maior parte dos recursos do Programa também foi alocada entre empresas estabelecidas na Grande Florianópolis, sendo responsável por 75\% dos recursos distribuídos para Santa Catarina, em 2008, e por 53\%, em 2009. Em 2009, destacam-se as empresas estabelecidas nas regiões do Alto Vale do Itajaí (Blumenau e Timbó), com 16\% dos 
recursos, e uma empresa do Norte do Estado (Jaraguá do Sul), com 10\% dos recursos. Em 2008, os valores financiados oscilaram entre R\$ 938.756,56 e R\$3.129.715,80, e, em 2009, entre R\$511.156,80 e R\$ 2.297.600,00. A seguir, apresenta-se o Programa Juro Zero (PJZ) da FINEP.

\subsection{O PROGRAMA JURO ZERO (PJZ) DA FINEP}

Cumpre inicialmente, como forma de contextualização, apresentar, sucintamente, a Financiadora de Estudos e Projetos (FINEP), que gerencia o Programa Juro Zero, cujas Micro e Pequenas Empresas Inovadoras catarinenses beneficiadas por esse Programa configuram-se como objeto de estudo desta pesquisa. A FINEP, criada em 24 de julho de 1967, é uma empresa pública vinculada ao MCT, cujo objetivo é promover e financiar a inovação e a pesquisa científica e tecnológica, cujos resultados possam contribuir para a expansão do conhecimento e/ou a geração de impactos positivos no desenvolvimento sócio-econômico brasileiro. Nesse sentido, a FINEP busca: (i) expandir e aperfeiçoar o Sistema Nacional de CT\&l, incentivando o aumento da produção do conhecimento e da capacitação científica e tecnológica do País; (ii) estimular e apoiar atividades que promovam a ampliação da capacidade de inovação, de geração e incorporação de conhecimento científico e tecnológico na produção de bens e serviços; e, (iii) colaborar para o sucesso das metas definidas pelas políticas públicas do Governo Federal.

Para atingir seus objetivos, o apoio da FINEP abrange todas as etapas e dimensões do ciclo científico e tecnológico: pesquisa básica, pesquisa aplicada, inovações e desenvolvimento de produtos, serviços e processos. Esses apoios são efetuados por meio de financiamentos reembolsáveis e não reembolsáveis. Os financiamentos reembolsáveis são realizados com recursos próprios ou provenientes de repasses de outras fontes, como o Fundo Nacional de Desenvolvimento (FND) e o Fundo de Amparo ao Trabalhador (FAT).

Uma das linhas de financiamentos reembolsáveis da FINEP é o Programa Juro Zero (PJZ) cujo objetivo é apoiar os projetos desenvolvidos por MPEls, que representem uma inovação em seu setor de atuação, seja nos aspectos comerciais, nos gerenciais, nos de processos ou nos de produtos e/ou serviços. Sendo assim, o PJZ visa estimular o desenvolvimento das MPEls brasileiras, viabilizando o acesso ao crédito por meio de financiamentos de longo prazo, com juro real igual a zero e sem a necessidade de apresentação de garantias reais. A FINEP segue a definição de inovação constante do artigo 17 da Lei ${ }^{\circ}$ 11.196/2005:

Considera-se inovação tecnológica a concepção de novo produto ou processo de fabricação, bem como a agregação de novas funcionalidades ou características ao produto ou processo que implique melhorias incrementais e efetivo ganho de qualidade ou produtividade, resultando maior competitividade no mercado.

O PJZ financia a inovação de empresas dos setores de semicondutores, software, bens de capital, fármacos e medicamentos, biotecnologia, nanotecnologia, 
biomassa, maricultura, turismo e entretenimento. São itens financiáveis os novos investimentos constantes do projeto/plano de negócios da empresa, desde que estes itens estejam diretamente vinculados às atividades de desenvolvimento da inovação tecnológica, compreendendo desde a pesquisa básica até a introdução do novo produto no mercado.

O PJZ oferece financiamentos entre R\$ 100 mil e R\$ 900 mil, sendo este último valor limitado a 30\% da Receita Operacional Bruta da empresa no ano fiscal anterior à data do pedido de financiamento. A amortização do valor financiado será efetuada em 100 meses, ou seja, 100 parcelas mensais e consecutivas, buscando viabilizar reflexos positivos no foco de análise investigado (impacto da inovação no desempenho econômico-financeiro), evidenciando a importância da inovação tecnológica para desenvolvimento e fortalecimento das MPEls por meio do PJZ da FINEP, cujo valor será corrigido pelo Índice Nacional de Preços ao Consumidor Amplo (IPCA), e o prazo de execução dos investimentos a serem realizados no projeto da empresa deve ter abrangência de 12 ou 18 meses.

Como o objetivo do PJZ é financiar projetos inovadores das MPEs, para classificação do porte das empresas é utilizada a Portaria $n^{\circ}$ 176/2002 do Ministério do Desenvolvimento, Indústria e Comércio Exterior, conforme definição apresentada no item 2.1. Para implementação inicial ( $1^{\text {a }}$ fase) do PJZ, a FINEP lançou a Chamada Pública MCT/FINEP - Programa Juro Zero, em janeiro de 2004, com o objetivo de selecionar cinco instituições ou consórcios de instituições para serem seus parceiros estratégicos na implementação do programa em determinadas regiões do país, conforme destaca o Quadro 1.

\begin{tabular}{|c|c|c|}
\hline Parceiro & $\begin{array}{l}\text { Região de } \\
\text { Atuação (UF) }\end{array}$ & Setores Apoiados \\
\hline Núcleo de Gestão do Porto Digital & Pernambuco & software (TIC) \\
\hline Federação das Indústrias de Minas Gerais - FIEMG & Minas Gerais & \multirow{4}{*}{$\begin{array}{c}\text { semicondutores } \\
\text { (microeletrônica); } \\
\text { software (TIC); bens } \\
\text { de capital; fármacos } \\
\text { e medicamentos; } \\
\text { biotecnologia; } \\
\text { nanotecnologia; } \\
\text { biomassa; outros (desde } \\
\text { que caracterizada a } \\
\text { inovação). }\end{array}$} \\
\hline $\begin{array}{l}\text { Federação das Indústrias do Estado do Paraná - } \\
\text { FIEPR }\end{array}$ & Paraná & \\
\hline $\begin{array}{l}\text { Fundação de Amparo à Pesquisa do Estado da Bahia } \\
\text { - FAPESB }\end{array}$ & Bahia & \\
\hline $\begin{array}{l}\text { Associaç̧ão Catarinense de Empresas de Tecnologia - } \\
\text { ACATE }\end{array}$ & Santa Catarina & \\
\hline
\end{tabular}

Quadro 1 - Parceiros estratégicos, região de atuação e setores apoiados pela $1^{\text {a }}$ fase do PJZ Fonte: Adaptado de FINEP (2009).

Segundo a FINEP, o volume de recursos disponibilizados para cada região não ultrapassará R\$ 20 milhões, que serão liberados aos projetos a serem financiados, conforme pactuado com os parceiros estratégicos e respeitada a disponibilidade 
orçamentária da FINEP. Desde 2006, quando o PJZ entrou em operação, até o mês de maio de 2009, já foram aprovados 62 projetos no País, totalizando R\$ 33,5 milhões.

Objetivando estimular a capacidade inovadora das MPEls de outras regiões, em 31 de julho de 2009, a FINEP abre uma nova Chamada Pública com o objetivo de selecionar novos parceiros estratégicos. Como resultado dessa chamada, foram selecionados quatro novos parceiros: a Caixa Estadual S/A, do Rio Grande do Sul; a Secretaria de Desenvolvimento do Estado de São Paulo; a Fundação de Amparo à Pesquisa do Espírito Santo; e a Investe Rio, agência de fomento do Estado do Rio de Janeiro. Com o resultado da chamada, o Programa passa a operar em nove estados brasileiros - Santa Catarina, Paraná, Bahia, Minas Gerais, Pernambuco, Rio de Janeiro, São Paulo, Rio Grande do Sul e Espírito Santo.

Em Santa Catarina (contexto estudado), o convênio de cooperação institucional foi firmado entre a Associação Catarinense de Empresas de Tecnologia (ACATE) e a FINEP, em agosto de 2006. A parceria entre a ACATE e a FINEP fez com que Santa Catarina fosse responsável pelo maior número de projetos aprovados no PJZ em todo o Brasil, com aproximadamente $50 \%$ dos projetos aprovados nacionalmente, e que a ACATE obtivesse, em 2008, o reconhecimento da financiadora sendo considerada com melhor desempenho entre parceiros dos estados de Minas Gerais, Paraná, Bahia e Pernambuco. No Estado de Santa Catarina, até outubro de 2009, o PJZ já beneficiou 31 empresas. Juntas, as empresas receberam $\mathrm{R} \$ 17.289 .088,69$ para investirem em inovação de processos, produtos e serviços. Na sequência, discorre-se sucintamente sobre a avaliação econômico-financeira de empresas.

\subsection{AVALIAÇÃO ECONÔMICO-FINANCEIRA DE EMPRESAS}

Como forma de avaliar o desempenho econômico-financeiro, as empresas utilizam-se dos dados apresentados em seus demonstrativos contábeis. Nesse sentido, Assaf Neto (2010) destaca que por meio dos demonstrativos contábeis elaborados por uma empresa pode-se extrair, por um processo de análise e interpretação, uma série de informações e conclusões sobre a sua posição financeira e econômica. Dessa forma a Contabilidade tem um papel fundamental no processo decisório de seus diversos usuários - administradores da empresa, prestadores de serviço, fornecedores de materiais de consumo, fornecedores de bens de capital, instituições financeiras, sócios/acionistas da empresa, futuros investidores, autoridades públicas, entre outros (MOROZINI, 2005) - que utilizam os demonstrativos contábeis para atender suas necessidades de informações.

ludícibus (2009) comenta que a análise contábil-financeira é a arte de saber extrair relações úteis, para seus objetivos, dos demonstrativos contábil-financeiros tradicionais e de suas extensões e detalhamentos. Por sua vez, Morozini (2005) lembra que os processos de análises evidenciam a situação econômico-financeira das empresas, que acabam por desnudar-se pelos indicadores, fatores que, analisados no contexto passado, podem evidenciar uma tendência para o futuro da empresa, demonstrando as causas de possível sucesso ou insucesso. 
Os indicadores econômico-financeiros propostos por Matarazzo (2007), que utilizam como principal fonte de informação os demonstrativos contábeis, são divididos em três grupos: Liquidez, Estrutura de Capital e Rentabilidade, conforme apresenta o Quadro 2.

\begin{tabular}{|c|c|c|}
\hline ÍNDICES DE LIQUIDEZ & FÓRMULA & O QUE INDICA \\
\hline Liquidez Seca (LS) & $\frac{A C-\text { Estoques }}{P C}$ & $\begin{array}{l}\text { Quanto a empresa possui em disponibilidades, } \\
\text { aplicações financeiras a curto prazo e duplicatas a } \\
\text { receber, para fazer face a seu passivo circulante. }\end{array}$ \\
\hline Liquidez Corrente (LC) & $\frac{A C}{P C}$ & $\begin{array}{l}\text { Quanto a empresa possui em dinheiro mais bens e } \\
\text { direitos realizáveis no curto prazo, comparado com } \\
\text { suas dívidas a serem pagas no mesmo período. }\end{array}$ \\
\hline Liquidez Geral (LG) & $\frac{A C+R L P}{P C+E L P}$ & $\begin{array}{l}\text { Quanto a empresa possui em dinheiro, bens e } \\
\text { direitos realizáveis a curto e longo prazo, para } \\
\text { fazer face às suas dívidas totais. }\end{array}$ \\
\hline $\begin{array}{l}\text { ÍNDICES DE ESTRUTURA DE } \\
\text { CAPITAL } \\
\end{array}$ & FÓRMULA & O QUE INDICA \\
\hline $\begin{array}{l}\text { Composição do } \\
\text { Endividamento (CE) }\end{array}$ & $P C \stackrel{P C}{+E L P}$ & $\begin{array}{l}\text { Estrutura do passivo exigível da empresa; ou seja, } \\
\text { do volume de suas dívidas, qual a porcentagem } \\
\text { que deve ser paga a curto e longo prazo. }\end{array}$ \\
\hline $\begin{array}{l}\text { Imobilização do Patrimônio } \\
\text { Líquido (IPL) }\end{array}$ & $\frac{\mathrm{AP} \times 100}{\mathrm{PL}}$ & $\begin{array}{l}\text { Quanto do patrimônio líquido da empresa está } \\
\text { aplicado no ativo permanente. }\end{array}$ \\
\hline $\begin{array}{l}\text { Participação de Capitais } \\
\text { de Terceiros (PCT) }\end{array}$ & $\frac{P C+E L P \times 100}{P L}$ & $\begin{array}{l}\text { O percentual de capital de terceiros em relação } \\
\text { ao patrimônio líquido, retratando a dependência } \\
\text { da empresa em relação aos recursos externos. }\end{array}$ \\
\hline $\begin{array}{l}\text { Imobilização dos recursos } \\
\text { não correntes (IRNC) }\end{array}$ & $P L \frac{A P}{+E L P}$ & $\begin{array}{l}\text { Que percentual de recursos não correntes a } \\
\text { empresa aplicou no ativo permanente. }\end{array}$ \\
\hline ÍNDICES DE RENTABILIDADE & FÓRMULA & O QUE INDICA \\
\hline Giro do Ativo (GA) & $\frac{V L}{A T}$ & $\begin{array}{l}\text { Quanto a empresa vendeu para cada } \$ 1 \text { de } \\
\text { investimento total. }\end{array}$ \\
\hline $\begin{array}{l}\text { Retorno sobre o Investimento } \\
\text { total (ROI) ou Retorno } \\
\text { Sobre o Ativo (RSA) ou } \\
\text { Rentabilidade do Ativo }\end{array}$ & $\frac{\mathrm{LL} \times 100}{A T}$ & $\begin{array}{l}\text { Retorno verificado no total do investimento } \\
\text { efetuado pela empresa, ou seja, a capacidade que } \\
\text { os ativos apresentam de gerar lucros. }\end{array}$ \\
\hline $\begin{array}{l}\text { Retorno sobre o Patrimônio } \\
\text { Líquido (RSPL) ou } \\
\text { Rentabilidade do Patrimônio } \\
\text { Líquido ou Return on Equity } \\
\text { (ROE) }\end{array}$ & $\frac{\mathrm{LL} \times 100}{\mathrm{PL}}$ & $\begin{array}{l}\text { Quanto a empresa obtém de lucro para cada } \$ \\
100 \text { de capital próprio investido, em média, no } \\
\text { exercício. }\end{array}$ \\
\hline $\begin{array}{l}\text { Retorno Sobre as Vendas } \\
\text { (RSV) ou Margem Líquida ou } \\
\text { Rentabilidade das Vendas }\end{array}$ & $\frac{\mathrm{LL} \times 100}{\mathrm{VL}}$ & $\begin{array}{l}\text { Quanto a empresa obtém de lucro para cada } \$ 100 \\
\text { vendidos. }\end{array}$ \\
\hline
\end{tabular}

Quadro 2 - Indicadores de avaliação econômico-financeira

Fonte: adaptado de Matarazzo (2007), Assaf Neto (2010) e Silva (2010).

Os indicadores de avaliação econômico-financeira expostos no Quadro 2 foram utilizados na presente pesquisa pelo fato dos mesmos serem considerados por Matarazzo (2007) como suficientes para uma adequada avaliação econômica e financeira de empresas.

Em linhas gerais, por meio dos índices de liquidez pode-se medir a capacidade 
da empresa em liquidar seus compromissos nos vencimento, ou seja, pode-se afirmar que a liquidez de uma empresa é medida pela sua capacidade para satisfazer suas obrigações de curto prazo, na data do vencimento (GITMAN, 2002). Dessa forma, os índices de liquidez e solvência relacionam grupos patrimoniais do Balanço e possibilitam a avaliação da capacidade de pagamento das dívidas existentes na empresa.

Quanto aos indicadores de estrutura de capital ou de endividamento, estes são utilizados especialmente para avaliar a proporção de capital próprio e o capital de terceiros existentes no passivo da empresa (ASSAF NETO, 2010), e dessa forma, estes indicadores estão diretamente relacionados com a estratégia adotada pela empresa para atender às necessidades financeiras com investimento, financiamento e distribuição de dividendos (MOROZINI, 2005).

Já os índices de rentabilidade são utilizados para medir a capacidade econômica da empresa, ou seja, proporcionam a interpretação e análise dos resultados auferidos pela empresa, expressos pela relação entre o lucro da empresa com os vários itens, dependendo do objetivo da análise (ASSAF NETO, 2010). Em outras palavras, Morozini (2005, p. 66) diz que "quando se trata dos índices de rentabilidade, o assunto é a eficiência com que os ativos são geridos na empresa e evidenciados no Balanço Patrimonial".

\section{MÉTODO E PROCEDIMENTOS DA PESQUISA}

Os delineamentos desta pesquisa deram-se em função dos objetivos, dos procedimentos e da abordagem do problema. No que concerne aos objetivos, esta pesquisa consiste de um estudo do tipo descritivo (GIL, 1999), a fim de analisar o impacto do projeto inovador financiado pelo PJZ da FINEP no desempenho econômicofinanceiro das MPEls catarinenses, o qual foi realizado por meio de um estudo de casos múltiplos (RICHARDSON, 1999), com abordagem qualitativa-quantitativa dos dados (RICHARDSON, 1999).

0 presente estudo foi realizado com as $31 \mathrm{MPEls}$ beneficiadas na $1^{\text {a }}$ fase do Programa Juro Zero (PJZ) da FINEP até o mês de outubro de 2009. Convém destacar que quatro empresas não finalizaram o projeto até outubro/2009 e que cinco empresas não aceitaram participar da pesquisa. Cabe ressaltar ainda que a investigação do perfil das MPEls catarinenses beneficiadas pelo PJZ e das particularidades dos projetos financiados compreendeu as $31 \mathrm{MPEls}$, enquanto que a descrição da inovação gerada e da avaliação do desempenho econômico-financeiro das MPEls com a implementação do projeto financiado pelo PJZ restringiu-se a $22 \mathrm{MPEls}$. Assim, os resultados encontrados na pesquisa não são generalizáveis, sendo as informações encontradas válidas apenas para as empresas em estudo.

Para a coleta de dados, foram utilizados diferentes instrumentos de 
pesquisa de natureza primária (entrevista) e de natureza secundária (análise de documentos, questionário com questões fechadas e questionário com questões abertas) (RICHARDSON, 1999). Inicialmente, no início de outubro de 2009, realizouse uma entrevista de aproximadamente duas horas com a gerente de projetos da ACATE, responsável pelo gerenciamento dos projetos financiados pelo PJZ em Santa Catarina.

A seguir, foi enviado por correio uma Carta de Aceite (Termo de Consentimento) para as 27 empresas catarinenses beneficiadas pelo Programa que haviam finalizado os projetos financiados pelo PJZ.

Nessa ocasião, foi solicitado o retorno pelo correio para a ACATE da Carta de Aceite assinada pelo gestor da empresa, concordando em participar da pesquisa, e requerida uma cópia da última alteração do Contrato Social ou Estatuto Social e dos Demonstrativos Contábeis - Balanço Patrimonial (BP) e a Demonstração do Resultado do Exercício (DRE) do período anterior a submissão do projeto, do ano da submissão e do período posterior ao financiamento do PJZ.

O retorno da Carta de Aceite, juntamente com as cópias dos documentos mencionados, implicava a autorização para análise dos documentos da empresa que estão sob a guarda da gerente de projetos da ACATE desde a submissão da proposta do projeto pela empresa ao Programa (disponível no Portal do PJZ da FINEP) para avaliação interna pelo parceiro estratégico. Até a primeira semana de novembro de 2009, 22 empresas retornaram a Carta de Aceite assinada e a documentação solicitada.

Em seguida, a ACATE liberou o acesso para análise dos documentos das respectivas empresas sob sua responsabilidade, desde que mantido o sigilo das denominações sociais das MPEls. Após os procedimentos da análise dos documentos das empresas, foram enviados por correio eletrônico dois questionários aos gerentes de projeto das 22 MPEls. O primeiro, com questões fechadas, reúne informações sobre o caráter inovador das MPEls, com retorno de $100 \%$.

O segundo questionário, com questões abertas, reúne informações sobre os aspectos tecnológicos e grau de inovação inerente ao projeto e sobre os reflexos econômicos nas MPEls com a implementação do projeto inovador, com retorno de $86 \%$ o que equivale ao retorno de 19 questionários válidos.

Para a análise do desempenho econômico-financeiro das MPEls catarinenses beneficiadas pelo PJZ, a presente pesquisa utilizará a análise das Demonstrações Contábeis (Balanço Patrimonial e Demonstração do Resultado do Exercício) das empresas por meio do cálculo e interpretação: (i) dos 11 indicadores sugeridos por Matarazzo (2007) como suficientes para uma adequada avaliação econômica e financeira de empresas; e, (ii) da fórmula Du Pont, conforme Quadro 3. 


\begin{tabular}{|c|l|}
\hline \multirow{2}{*}{ Índices de Liquidez } & $\begin{array}{l}\text { - Liquidez Geral (LG) } \\
\text { - Liquidez Corrente (LC) } \\
\text { - Liquidez Seca (LS) }\end{array}$ \\
\hline $\begin{array}{c}\text { Índices de Estrutura } \\
\text { de Capital }\end{array}$ & $\begin{array}{l}\text { - Participação de Capital de Terceiros (Endividamento) (PCT) } \\
\text { - Composição do Endividamento (CE) } \\
\text { - Imobilização do Patrimônio Líquido (IPL) } \\
\text { - Imobilização dos Recursos não Correntes (IRNC) }\end{array}$ \\
\hline $\begin{array}{c}\text { Índices de } \\
\text { Rentabilidade }\end{array}$ & $\begin{array}{l}\text { - Giro do Ativo (GA) } \\
\text { - Rentabilidade do Ativo (RA) } \\
\text { - Rentabilidade do Patrimônio Líquido (RPL) } \\
\text { - Retorno sobre o Patrimônio Líquido (Du Pont) }\end{array}$ \\
\hline
\end{tabular}

Quadro 3 - Resumo dos indicadores econômico-financeiros utilizados na pesquisa Fonte: Adaptado de Matarazzo (2007), com inclusão da análise Du Pont.

\section{RESULTADOS E DISCUSSÃO}

Para a consecução do objetivo deste trabalho, nesta seção apresentam-se os resultados da pesquisa em termos de seus quatro objetivos específicos, quais sejam: (i) caracterizar as MPEls catarinenses beneficiadas pelo PJZ; (ii) descrever as particularidades dos projetos financiados pelo PJZ; (iii) identificar aspectos da inovação desenvolvidos nas MPEls financiadas pelo PJZ; e, (iv) avaliar as alterações do desempenho econômico-financeiro das MPEls com a implementação do projeto inovador financiado pelo PJZ. Para melhor entendimento dos resultados, os dados foram agrupados em quadros, tabelas e figuras.

\subsection{BREVE RELATO DAS MPEIS CATARINENSES PARTICIPANTES PJZ}

Para a descrição do perfil das $31 \mathrm{MPEls}$ catarinenses participantes da $1^{\text {a }}$ fase do Programa Juro Zero da FINEP, apresentam-se em seguida os seguintes focos de análise: porte, tipo de sociedade, localização, setor de atuação e classificação por verticais.

Para participar do Programa é pré-requisito que a empresa tenha apurado uma Receita Operacional Bruta (ROB) de, no mínimo, $\mathrm{R} \$ 333.333,34$, e, no máximo, de $\mathrm{R} \$ 10.500 .000,00$ no ano fiscal anterior à data do pedido do financiamento. Por meio do valor da ROB, o Programa qualifica as empresas como micro ou pequena empresa. Foi possível constatar que, no Estado de Santa Catarina, a maioria das 31 empresas financiadas pelo PJZ (81\%) é de pequeno porte. Ressalta-se que o PJZ considera como pequena empresa aquela cuja ROB anual seja superior a $\mathrm{R} \$ 1.200 .000,01$ e inferior 
ou igual a $\mathrm{R} \$ 10.500 .000,00$.

O Novo Código Civil determina que as empresas devam se adequar a um dos seguintes tipos societários: sociedade simples, sociedade em nome coletivo, sociedade em comandita simples, sociedade limitada, sociedade anônima e sociedade em comandita por ações. Com relação aos tipos societários de constituição das 31 empresas catarinenses financiadas pelo PJZ, observa-se que $87 \%$ das empresas catarinenses beneficiadas pelo PJZ são constituídas como sociedade limitada, e $13 \%$ são constituídas como sociedade anônima. Ressalta-se que dentre os seis tipos societários definidos pelo Novo Código Civil houve a predominância de somente dois tipos societários entre as empresas beneficiadas pelo PJZ no Estado de Santa Catarina. Torna-se ainda importante ressaltar o fato de que, apesar de o Programa ser direcionado às MPEls, houve ocorrência de quatro sociedades anôminas.

Quanto à localização das empresas beneficiadas pelo PJZ em Santa Catarina, verifica-se que os municípios com maiores índices de projetos inovadores financiados pelo PJZ foram Florianópolis (58\%) e Joinville (20\%). Juntos, os municípios representam $78 \%$ dos projetos aprovados. Este resultado corrobora com os dados da Associação Brasileira das Empresas de Software (ABES) que afirma que no Estado de Santa Catarina, as cidades de Joinville, Florianópolis (Capital da Inovação) e Blumenau lideram o ranking dos polos de TI de Santa Catarina (ABES, 2009).

No que tange ao setor de atuação e à classificação por verticais das MPEls observa-se que $52 \%$ das empresas financiadas pelo PJZ no Estado de Santa Catarina atuam no setor de software (TIC), seguido do setor de bens de capital com 23\%, que representam, conjuntamente, $75 \%$ do total de empresas beneficiadas. A preponderância do setor de software constatada na pesquisa corrobora com os dados do MCT (2001), que afirma que o setor de software representa aproximadamente 70\% do total de EBTs no Brasil. O estudo realizado por Gallon e Ensslin (2008, p. 11) em EBTs incubadas catarinenses também constatou que "a maior parte das EBTs atua na área de informática, mais especificamente na área de desenvolvimento de software." Foi possível verificar ainda que MPEls catarinenses analisadas desenvolvem soluções para diversos ramos de atuação. Dessa forma, pode-se afirmar que os produtos, serviços ou processos inovadores financiados pelo PJZ devem beneficiar os respectivos segmentos, em especial aos segmentos: industrial (30\%), agronegócio (11\%), segurança (10\%) e internet e serviços $(10 \%)$, importantes para a economia brasileira. O que se verifica é que o PJZ além de promover o desenvolvimento das MPEls também promove possibilidades de melhora de produtividade e competitividade a empresas de diversos ramos de atuação em todos os estados brasileiros por meio do apoio do Programa ao desenvolvimento de soluções inovadoras de TI.

\subsection{DESCRIÇÃO DAS PARTICULARIDADES DOS PROJETOS FINANCIADOS PELO PJZ}

Para a descrição das particularidades dos 31 projetos catarinenses, apresentamse os seguintes focos de análise: prazo de execução, valor contratado e itens 
financiados pelo Programa. Nesta subseção, as análises englobam todos os projetos aprovados pelo PJZ até outubro de 2009 , independente de estes se encontrarem em execução ou concluídos.

A Tabela 1 apresenta o ano de envio dos projetos inovadores propostos pelas MPEls catarinenses aprovados pelo PJZ da FINEP.

Tabela 1 - Ano de envio dos projetos propostos pelas MPEls aprovados pelo PJZ

\begin{tabular}{c|c|c|c|c}
\hline 2006 & 2007 & 2008 & 2009 & TOTAL \\
\hline 3 & 16 & 6 & 6 & 31 \\
\hline
\end{tabular}

Fonte: Dados da pesquisa.

$O$ ano de envio dos projetos inovadores propostos pelas MPEls catarinenses aprovados pelo PJZ da FINEP e o ano da liberação da primeira parcela do financiamento às empresas coincidem, pois a liberação da primeira parcela é efetuada aproximadamente 10 dias após a assinatura do contrato entre as partes (MPEl e FINEP). Por meio das informações constantes na Tabela 1, verifica-se que a maior parte $(51,61 \%)$ dos projetos inovadores catarinenses teve início em 2007. Ressalta-se que o convênio entre a FINEP e a ACATE (parceira estratégica no Estado de Santa Catarina) foi firmando em agosto de 2006. Torna-se importante destacar que, dos 31 projetos inovadores catarinenses encaminhados para avaliação entre 2006 e 2009, 27 (87,10\%) foram concluídos até o mês de realização da presente pesquisa (outubro/2009).

No que tange aos investimentos a serem realizados, de acordo com os critérios do Programa, os projetos poderão abranger um período de execução de 12 ou 18 meses. Após a realização da análise dos projetos foi possível verificar que a maioria (87\%) das MPEls optou por executar o projeto no prazo de 18 meses - prazo máximo estabelecido pelo PJZ, não sendo possível prorrogação do prazo.

Antes de evidenciar os valores financiados pelo PJZ para execução dos projetos inovadores, cabe lembrar que o Programa financia projetos entre R\$100 mil (valor mínimo) e R\$ 900 mil (valor máximo), sendo o valor a ser financiado limitado a $30 \%$ da ROB da empresa no ano fiscal anterior à data do pedido de financiamento. Verificou-se que o valor com maior índice de contratação foi entre R\$750.000,01 a R\$ $900.000,00$, valor este contratado por $32 \%$ das MPEIs beneficiadas, seguido pelo valor de $\mathrm{R} \$ 450.000,01$ a $R \$ 600.000,00$ com $23 \%$. Ressalta-se que entre R\$100.000,00 a $\mathrm{R} \$ 150.000,00$ não houve contratação. Em linhas gerais, nota-se que $71 \%$ dos valores financiados oscilam entre $\mathrm{R} \$ 450.000,01$ a $\mathrm{R} \$ 900.000,00$.

Por fim, apresentam-se as rubricas financiadas pelo PJZ para o desenvolvimento dos produtos, serviços ou processos inovadores pela MPEls beneficiadas. Conforme determinam as regras do programa, são aceitos como financiáveis os itens relativos aos novos investimentos constantes do projeto ou plano de negócios da empresa, desde que estes itens estejam direta ou indiretamente vinculados às atividades de inovação tecnológica. Dessa forma, foram financiados na $1^{\text {a }}$ fase do PJZ os seguintes itens: gastos com obras, recursos para a aquisição de equipamentos nacionais e importados, recursos para aquisição de matéria-prima, gastos com pessoal, despesas 
de contratação de serviços de consultoria, recursos para investimento em treinamentos dos colaboradores, aquisição de software, contratação de serviços de terceiros, despesas com viagens e estadas, e outras despesas necessárias ao desenvolvimento do projeto.

A primeira fase do PJZ financiou até outubro de 2009 o valor total de R\$ 17.289.088,69. Observou-se que a rubrica de maior cobertura pelo financiamento refere-se à Despesa com Pessoal (contratação de novos empregados e capacitação de empregados atuais alocados na área de P\&D), que representa $47 \%$ do valor total financiado. Esse fato vem de encontro aos anseios da FINEP, já que os recursos do PJZ em questão são oriundos do Fundo de Amparo ao Trabalhador (FAT). Na sequência, aparecem os investimentos financiados nas MPEls em Equipamentos Nacionais (11\%), Serviços de Consultoria (9\%) e Matéria-Prima/Insumos (8\%). Outro aspecto a ser destacado é que no setor de TI a mão-de-obra especializada é o principal insumo para o desenvolvimento e manutenção de atividades relacionadas à P\&D de produtos, serviços e processos inovadores e, em linhas gerais, as Despesas com Pessoal são as mais representativas entre as Despesas Operacionais de EBTs.

Na sequência, apresenta-se a descrição da inovação gerada nas MPEls com o projeto financiado pelo PJZ. Torna-se importante ressaltar que os resultados apresentados nas seções seguintes dizem respeito às 22 empresas que finalizaram os projetos financiados até outubro de 2009 (período de realização da pesquisa) e que concordaram em participar da pesquisa.

\subsection{DESCRIÇÃO DA INOVAÇÃO GERADA NAS MPEIS COM O PROJETO FINANCIADO PELO PJZ}

Para a análise da inovação desenvolvida com o projeto financiado pelo PJZ nas MPEls (terceiro objetivo específico), considerou-se o registro de marcas e patentes pelas empresas.

A inovação - desenvolvida nas atividades de pesquisa para a geração de novo conhecimento - é materializada em novos produtos, serviços e/ou processos inovadores. Como forma de proteção à propriedade intelectual, foi possível verificar que $22,73 \%$ das MPEls catarinenses financiadas pelo PJZ efetuaram o registro de marcas e de patentes, sendo que, das cinco empresas em questão, duas delas efetuaram tanto o registro de marcas como de patente do produto financiado pelo PJZ. Diante da importância da competitividade das MPEls brasileiras para o desenvolvimento do País, este quadro revela a geração do conhecimento, por meio da inovação e da capacitação tecnológica, e a gestão do conhecimento nas MPEls catarinenses beneficiadas pelo PJZ da FINEP. Este percentual (22,73\%) encontra consonância com os achados de outras pesquisas que investigaram o registro de marcas e patentes por EBTs incubadas (FERREIRA; OLIVA; CORREA, 2009; GALLON; ENSSLIN; SILVEIRA, 2009). $\mathrm{Na}$ pesquisa de Ferreira, Oliva e Correa (2009) com EBTs participantes do Centro Incubador de Empresas Tecnológicas (CIETEC), foi constatado que o número médio de patentes solicitadas pelas EBTs desde sua criação é baixo $(1,1)$, e equivale que cada uma das nove EBTs solicitou apenas uma patente desde sua criação. Os autores ainda contam que esse resultado não é diferente do encontrado em outras pesquisas e 
afirmam que "notoriamente, o Brasil ocupa uma posição incômoda quando comparado neste quesito com outros países em desenvolvimento. Em 2000, a Coréia registrou aproximadamente 3.500 patentes nos EUA e o Brasil menos de 100" (Ibid., p. 12). Gallon, Ensslin e Silveira (2009), em seu estudo com EBTs participantes do processo de incubação de uma incubadora tecnológica catarinense, também constataram que é baixo o número de registro de marcas e/ou patentes pelas EBTs incubadas, mas advertem que esse quadro pode ser justificado em virtude de as EBTs serem, em sua maioria, iniciantes e possuírem produtos nos estágios iniciais do ciclo de vida.

Outro aspecto observado na pesquisa e que deve ser ressaltado nesta subseção é o fato de que $42,11 \%$ das MPEls analisadas firmaram parcerias com instituições de pesquisa para a consecução do projeto inovador financiado pelo PJZ/FINEP. As parceiras e/ou cooperações institucionais foram estabelecidas entre as MPEls e organizações de pesquisa e desenvolvimento tecnológico, universidades brasileiras e estrangeiras, instituições internacionais que tratam de questões estratégicas relacionadas a TICs e a empresas públicas ou privadas. Esse percentual diverge dos achados do estudo desenvolvido por Miziara e Carvalho (2008) que perceberam que as atividades de parceria e cooperação dessa natureza são pouco frequentes nas EBTs, sendo predominantemente informal.

Para ilustrar os aspectos tecnológicos e o grau de inovação inerentes ao projeto que foi objeto do financiamento, apresenta-se Quadro 4.

\begin{tabular}{|c|c|}
\hline Empresa & Aspectos tecnológicos do projeto financiado e seu grau de inovação \\
\hline MPEI - 01 & $\begin{array}{l}\text { A tecnologia desenvolvida no projeto coloca a empresa na vanguarda de soluções e } \\
\text { possibilitou um grande diferencial para a área de atuação da empresa. }\end{array}$ \\
\hline MPEI - 02 & $\begin{array}{l}\text { A implementação de um projeto inovador como este nos obrigou a desenvolver em } \\
\text { conjunto com o INMETRO uma sistemática de aprovação de modelo para o produto } \\
\text { o produto financiado, uma vez que o regulamento brasileiro atual não contempla a } \\
\text { situação de nosso projeto. Nossa idéia foi acolhida pelo INMETRO por tratar-se de } \\
\text { idéia inovadora, desenvolvida por empresa brasileira, no Brasil, e que denota uma } \\
\text { tendência de mercado para o futuro. Todo este trabalho nos ajuda inclusive a construir } \\
\text { uma imagem perante os colaboradores internos e externos de empresa inovadora e } \\
\text { comprometida com a inovação. }\end{array}$ \\
\hline MPEI - 03 & $\begin{array}{l}\text { A empresa tem como propósito criar novos produtos e serviços a partir de novas } \\
\text { tecnologias desenvolvidas por outros. Nosso propósito é ser a empresa que } \\
\text { transformará essas novas tecnologias em produtos comerciais. Em sua história a } \\
\text { empresa apresenta todos os anos novidades em produtos de alta tecnologia. Para } \\
2009 \text { já foram desenvolvidos e lançados } 03 \text { novos produtos e viabilizou a aplicação no } \\
\text { Brasil da tecnologia NFC de celulares, já disponível em diversos países desenvolvidos. } \\
\text { Outros } 02 \text { já estão em fase de desenvolvimento, o que demonstra um elevado grau } \\
\text { de inovação. }\end{array}$ \\
\hline MPEI - 04 & Alto, pelo fato de haver um litígio internacional sobre a patente da inovação. \\
\hline MPEI - 05 & $\begin{array}{l}\text { A inovação tecnológica do produto financiado pelo programa está na metodologia } \\
\text { de rastreabilidade que utiliza uma técnica de "alvarás" para autorização do seu } \\
\text { funcionamento. São diversos os fatores que irão garantir a competitividade da empresa } \\
\text { no mercado. Entre elas estão o tempo de desenvolvimento, domínio tecnológico, } \\
\text { regulamentação, homologação, diferenciais exclusivos do sistema e rede de alianças. }\end{array}$ \\
\hline MPEI - 06 & $\begin{array}{l}\text { A solução desenvolvida com o apoio do PJZ possui um apelo positivo do ponto de } \\
\text { vista da inovação, visto que a solução começou a ser ofertada no mercado nacional } \\
\text { recentemente. Existem baixas barreiras de entrada aos produtos financiados, pois os } \\
\text { mesmos serão ofertados para os atuais clientes da empresa. }\end{array}$ \\
\hline
\end{tabular}


continuação ...

Empresa $\quad$ Aspectos tecnológicos do projeto financiado e seu grau de inovação

O risco tecnológico sempre está associado ao grau de inovação e agregação de valor, onde a empresa neste desenvolvimento procurou gerar nã̃o somente produtos inovadores mas também soluções integradas. Com isso a empresa conseguiu obter um

MPEI - 07 produto inovador em nível mundial para ambiente outdoor. Contudo com redução de impostos, barreiras de entrada e agregação de valor vigentes, a empresa atualmente tem um risco tecnológico menor, por estar em mesmo nível (atual) às tecnologias similares lançadas no exterior.

A inovação tecnológica do produto financiado pelo programa está na integração de MPEI - 08 hardware e software em uma única solução que contempla PABX IP, URA, sistema de discagem e sistema de gravação.

A área de telecomunicações, dentro do ambiente de negócios nacional e

internacional, é hoje uma das mais desenvolvidas, com uma alta taxa de atualização tecnológica. Isto reflete diretamente nas estratégias da empresa no que tange á

MPEI - 09 gestão de tecnologia e inovação. Por atuarmos em nicho de mercado, fortemente relacionado com questões regulatórias e mercadológicas, criamos na empresa uma área específica para gestão da inovação, que visa manter a empresa alinhada com as tendências tecnológicas de nosso mercado.

MPEI - 10 Com desenvolvimento de solução específica, conseguimos assim a fidelização dos clientes e criamos barreiras de entrada a concorrências.

MPEI - 11 Com os recursos do Programa desenvolvemos o protótipo do produto financiado e com esta estrutura conseguimos ainda a reengenharia de outros equipamentos da linha.

A utilização de novas tecnologias para o desenvolvimento do produto e a possibilidade

MPEI - 12 de utilização dessa tecnologia nos nossos demais produtos elevaram o grau de inovação da empresa. Sem as novas tecnologias, a médio prazo, todos os nossos produtos teriam dificuldades em continuar no mercado. Não houve aquisição de tecnologias de terceiros, $100 \%$ do desenvolvimento do produto foi feito na própria empresa.

A empresa conseguiu solidificar sua imagem de inovação no mercado que atua com o desenvolvimento dos produtos foco deste projéto. 0 uso da tecnologia de embalagem com atmosfera modificada foi aperfeiçoado pela empresa e esta ainda

MPEI - $13 \quad \begin{aligned} & \text { embalagem com atmosfera modificada foi aperfeiçoado pela empresa e esta ainda } \\ & \text { destaca-se como a única a utilizar esta tecnologia no Brasil. A parceria da empresa } \\ & \text { com alguns fornecedores também se tornou mais estreita em decorrência deste }\end{aligned}$

MPEI - $13 \quad \begin{aligned} & \text { embalagem com atmosfera modificada foi aperfeiçoado pela empresa e esta ainda } \\ & \text { destaca-se como a única a utilizar esta tecnologia no Brasil. A parceria da empre } \\ & \text { com alguns fornecedores também se tornou mais estreita em decorrência deste }\end{aligned}$ destaque.

\begin{tabular}{ll} 
MPEI - 14 & Não respondeu. \\
\hline & Existem dificuldades reconhecidas pelo departamento de projeto sobre o constante
\end{tabular} ajuste do projeto conforme cada tipo de biomassa. Dificuldade de formatar um

MPEI - 15 padrão de equipamento. Necessidade de aprimorar o conhecimento constante, quanto a adaptar a peletização para os inúmeros tipos de biomassa, assim como temos dificuldades em termos profissionais para fazer o setup de uma unidade de peletização.

Acreditamos que a inovação está diretamente associada ao mercado, o grau de exigência cada vez maior dos clientes faz com que antes de prosseguir, deve-se entender que inovação não precisa significar descoberta, mas diferencial que agrega

MPEI - 16 valor aos produtos ou serviços. Essa sutileza, que para alguns, pode pouco importar, para o detentor desse diferencial que estimula a criatividade dos colaboradores, investir em P\&D, representa o alcance de posição confortável frente ao cenário competitivo.

MPEI - 17 A empresa tem um dos seus focos em inovação e investe com recursos próprios em P\&D, o PJZ veio neste aspecto fomentar esta atividade.

O domínio da tecnologia do produto financiado pelo programa possibilitou o

MPEI - 18 desenvolvimento de outro projeto de menor complexidade técnica com previsão para lançamento em janeiro de 2010.

Um dos efeitos indiretos do projeto financiado é a divulgação da imagem da empresa

MPEI - 19 como parceira tecnológica ideal, levando soluções de TI modernas para empresas do setor energético. Essas mudanças ajudam a vencer barreiras de entrada em um mercado maduro e bastante conservador, como o setor elétrico.

Quadro 4 - Relato dos aspectos tecnológicos do projeto financiado e seu grau de inovação Fonte: Dados da pesquisa. 
Por meio das informações evidenciadas no Quadro 4 sobre os aspectos tecnológicos e o grau de inovação dos projetos das MPEls catarinenses financiados pelo PJZ da FINEP, percebe-se que a maioria das empresas tem por objetivo o desenvolvimento de novas soluções ou diferenciais tecnológicos que agreguem valor em seus produtos ou serviços de forma a atender as necessidades do mercado de atuação das respectivas MPEls. Pode-se observar também que em algumas empresas o produto ou serviço objeto de financiamento não possui produto similar no mercado nacional - o que revela seu baixo risco tecnológico - e que possibilitou a expansão da atuação da MPEI tanto no mercado nacional como no internacional.

\subsection{DESCRIÇÃO DA AVALIAÇÃO DO DESEMPENHO ECONÔMICO-FINANCEIRO DAS MPEIS COM A IMPLEMENTAÇÃO DO PROJETO INOVADOR FINANCIADO PELO PJZ}

Para a análise do impacto do projeto inovador no desempenho econômicofinanceiro, analisaram-se os seguintes demonstrativos contábeis das empresas: Balanço Patrimonial e Demonstração do Resultado do Exercício.

Ao analisar o faturamento das $22 \mathrm{MPEls}$ no período pré-financiamento, ano do financiamento e pós-financiamento constatou-se, que apesar de todas as empresas beneficiadas pelo PJZ enquadrarem-se como MPEs, elas apresentam Faturamento bastante diverso, oscilando entre $\mathrm{R} \$ 516.421,57$ (MPEI - 21) e R\$ 25.038.887,16 (MPEI - 11) no período pós-financiamento. Outro fato a ser destacado é que a maioria das empresas $(63,64 \%)$ aumentou consideravelmente seu patamar de Receita e que, em média, o Faturamento das MPEls aumentou em 49,13\% no período pós-financiamento em relação ao ano do financiamento. Tal constatação quantitativa enaltece a importância do financiamento de inovação tecnológica nas MPEls catarinenses por meio do PJZ da FINEP para o fortalecimento do setor tecnológico em Santa Catarina. A Tabela 2 apresenta a distribuição do Faturamento das empresas no mercado interno e externo nos anos de 2006, 2007 e 2008.

Tabela 2 - Faturamento das MPEls no mercado interno e externo

\begin{tabular}{|c|c|c|c|}
\hline Faturamento & 2006 & 2007 & 2008 \\
\hline Mercado interno & $\mathrm{R} \$ 77.211 .178,09$ & $\mathrm{R} \$ 95.542 .359,13$ & $\mathrm{R} \$ 132.892 .792,09$ \\
\hline Mercado externo & $\mathrm{R} \$ 2.922 .559,06$ & $\mathrm{R} \$ 3.282 .971,89$ & $5.886 .588,38$ \\
\hline TOTAL & $\mathrm{R} \$ 80.133 .737,15$ & $\mathrm{R} \$ 98.825 .331,02$ & $\mathrm{R} \$ 138.779 .380,47$ \\
\hline
\end{tabular}

Fonte: Dados da pesquisa.

Com relação as informações da Tabela 2 é possível verificar o aumento de $72,12 \%$ no faturamento do mercado interno se comparamos o ano de 2006 com o ano de 2008; e um aumento notável de 101,42\% no mercado externo no mesmo período. Fato que conforme mencionado por alguns gerentes de projeto, evidencia a difusão e/ou crescimento da comercialização dos produtos e serviços das empresas pesquisadas no mercado externo.

A seguir, os dados das análises de liquidez, endividamento e rentabilidade das 
MPEls foram manuseados em uma perspectiva quantitativa para estabelecer a Média e o Desvio Padrão (DP) com o intuito de mensurar o reflexo do financiamento obtido pelas empresas nas Demonstrações Contábeis das mesmas. O DP foi utilizado para avaliar a dispersão do conjunto de valores na análise de liquidez. Barbetta (2001, p. 102-103) comenta que ao comparar os DPs de vários conjuntos de dados, "podemos avaliar quais se distribuem de forma mais (ou menos) dispersa. O desvio padrão será sempre não negativo e será tão maior quanto mais disperso forem os valores observados." A Tabela 3 apresenta a análise de liquidez das MPEls analisadas.

Tabela 3 - Análise de liquidez das MPEls no período do ano do financiamento e do ano pósfinanciamento

\begin{tabular}{l|c|c|c|c}
\hline \multirow{2}{*}{ Índices de Liquidez } & \multicolumn{2}{c}{ Ano do financiamento } & \multicolumn{2}{c}{ Pós-financiamento } \\
\cline { 2 - 5 } & Média & Desvio Padrão & Média & Desvio Padrão \\
\hline Liquidez Geral & 1,44 & 0,95 & 1,57 & 0,60 \\
\hline Liquidez Corrente & 2,30 & 1,34 & 2,44 & 1,16 \\
\hline Liquidez Seca & 1,51 & 1,01 & 1,63 & 0,79 \\
\hline
\end{tabular}

Fonte: Dados da pesquisa.

Os índices de liquidez medem a capacidade de pagamento, avaliam a capacidade financeira para atender os compromissos assumidos com terceiros (GITMAN, 2002). Por sua vez, Silva (2010) relata que os índices de liquidez fornecem um indicador da capacidade da empresa de pagar suas dívidas, a partir da comparação entre os direitos realizáveis e as exigibilidades.

Com base na Tabela 3 nota-se que, em linhas gerais, a liquidez média das MPEls beneficiadas pelo PJZ em Santa Catarina melhorou no período do pósfinanciamento em relação ao exercício da concessão do financiamento pelas empresas, independentemente de se considerar somente o curto prazo (corrente e seca) ou inclusive o longo prazo (geral). Observa-se que mesmo no ano do financiamento a média dos índices de liquidez das MPEls revela que as mesmas possuíam capacidade financeira para saldar suas obrigações tendo melhora no período seguinte, que coincide com o período de desenvolvimento do projeto e, em vários casos, com o período de comercialização dos produtos e serviços inovadores oriundos dos projetos financiados pela FINEP, uma vez que o período de execução dos projetos financiados é de 12 ou 18 meses.

A situação financeira média confortável das empresas reveladas na Tabela 3 ratifica a avaliação econômico-financeira realizada, tanto pelo comitê interno da ACATE (parceira estratégica), como pelos consultores da FINEP. Outro fato a ser destacado é que a dispersão entre à liquidez é relativamente baixa, especialmente no que se refere à liquidez geral e à liquidez seca, principalmente no ano do pósfinanciamento.

A Tabela 4 apresenta a análise da estrutura de capital (endividamento) das MPEls. 
Tabela 4 - Análise da estrutura de capital (endividamento) das MPEls no período no período do ano do financiamento e do ano pós-financiamento

\begin{tabular}{l|c|c}
\hline Índices de Endividamento & $\begin{array}{c}\text { Ano do financiamento } \\
\text { (Média) }\end{array}$ & $\begin{array}{c}\text { Pós-financiamento } \\
\text { (Média) }\end{array}$ \\
\hline Endividamento & $229 \%$ & $312 \%$ \\
\hline Composição do Endividamento & $61 \%$ & $64 \%$ \\
\hline Imobilização do Patrimônio Líquido & $101 \%$ & $111 \%$ \\
\hline Imobilização dos Recursos não Correntes & $50 \%$ & $56 \%$ \\
\hline
\end{tabular}

Fonte: Dados da pesquisa.

Para Assaf Neto (2010), os índices de endividamento são usados para uma avaliação da proporção de capital próprio e de capital de terceiros existente no passivo da empresa, assim, quanto menor, melhor. Silva (2008) menciona que estes índices estão ligados às decisões financeiras de financiamento e investimento.

De acordo com a Tabela 4 percebe-se que, diferente da análise de liquidez, a análise da estrutura de capital média das MPEls catarinenses beneficiadas pelo PJZ piorou no período do pós-financiamento em relação ao exercício da concessão do financiamento, uma vez que os índices de endividamento aumentaram no período. Tal fato pode ser explicado pela contabilização do financiamento do PJZ obtido pela empresa. Especificamente em relação ao índice de imobilização dos recursos não correntes, conforme Matarazzo (2007), este não deve em regra ser superior a 100\% - como apontado na média das MPEls pesquisadas - pois mesmo que a empresa tenha necessidade de ativo circulante, deve sempre existir um pequeno excesso de recursos não correntes, em relação às imobilizações, destinado ao ativo circulante.

A Tabela 5 apresenta a análise da rentabilidade (lucratividade) das empresas catarinenses beneficiadas pela $1^{\text {a }}$ fase do Programa Juro Zero.

Tabela 5 - Análise da rentabilidade das MPEls no período em análise

\begin{tabular}{c|c|c}
\hline Índices de Rentabilidade & $\begin{array}{c}\text { Ano do financiamento } \\
\text { (Média) }\end{array}$ & $\begin{array}{c}\text { Pós-financiamento } \\
\text { (Média) }\end{array}$ \\
\hline Giro do Ativo & 1,39 & $14 \%$ \\
\hline Margem Líquida & $6 \%$ & $19 \%$ \\
\hline Rentabilidade do Ativo & $15 \%$ & $168 \%$ \\
\hline Rentabilidade do Patrimônio Líquido & $56 \%$ & $51 \%$ \\
\hline
\end{tabular}

Fonte: Dados da pesquisa.

Segundo Assaf Neto (2010), os índices de rentabilidade proporcionam a interpretação e análise dos resultados auferidos pela empresa e são expressos pela relação entre o lucro da empresa com vários itens, dependendo do objetivo da análise. Matarazzo (2007, p. 175) ainda menciona que "os índices deste grupo mostram qual a rentabilidade dos capitais investidos, isto é, quanto rendeu os investimentos e, portanto, qual o grau de êxito econômico da empresa".

Com base na Tabela 5 observa-se que, em linhas gerais, a rentabilidade média das MPEls beneficiadas pelo PJZ melhorou no período do pós-financiamento em 
relação ao exercício da concessão do financiamento, com destaque para o avanço da rentabilidade média do patrimônio líquido e do retorno sobre o patrimônio líquido (Du Pont) das empresas.

Dessa forma, pode-se conjeturar que a comercialização dos produtos e serviços inovadores oriundos dos projetos financiados, evidenciada por algumas empresas, contribuiu para a evolução da rentabilidade média das empresas. Especificamente em relação ao índice do giro do ativo, este é um dos principais indicadores da atividade da empresa, já que estabelece a relação entre as vendas do período e os investimentos totais efetuados na empresa, que estão representados pelo ativo total médio (SILVA, 2010). No caso das MPEls pesquisadas, o índice médio das mesmas melhorou no período pós-financiamento, passando de 1,39 para 1,47, indicando um nível superior de eficiência na utilização dos recursos aplicados pelas empresas.

Com o intuito de complementar a análise quantitativa apresentada o Quadro 5 revela algumas informações qualitativas concedidas pelas empresas relacionadas aos respectivos aspectos econômico-financeiros.

\begin{tabular}{|c|l|}
\hline Empresa & $\begin{array}{l}\text { Informaçães qualitativas concedidas pelas empresas relacionadas aos aspectos } \\
\text { econômico-financeiros }\end{array}$ \\
\hline MPEI - 01 & $\begin{array}{l}\text { A rentabilidade do negócio está na faixa de 30\%. O grau de endividamento da } \\
\text { empresa é baixo comparado às receitas e previsões de negócios. Atualmente } \\
\text { estamos em processo final de financiamento junto ao BRDE (BNDES) para } \\
\text { infraestrutura e expansão dos negócios. }\end{array}$ \\
\hline MPEI - 02 & $\begin{array}{l}\text { O nível de rentabilidade da empresa aumentou e as vendas da empresa estão cada } \\
\text { vez mais distribuídas por um grupo maior de clientes, diminuindo a dependência } \\
\text { em relação aos grandes clientes. A velocidade de crescimento do negócio e os } \\
\text { investimentos na formação de estoques para a manufatura de produtos, o longo } \\
\text { ciclo de produção dos produtos e a necessidade de investimentos em marketing } \\
\text { para a divulgação destes produtos demandam um capital de giro cada vez maior, } \\
\text { gerando pressões sobre o fluxo de caixa da empresa. Quando necessário a empresa } \\
\text { tem recorrido a linhas de crédito de curto prazo junto aos bancos comerciais. }\end{array}$ \\
\hline MPEI - 03 & $\begin{array}{l}\text { A empresa tem uma gestão financeira e administrativa bastante conservadora, } \\
\text { evitando captação de recursos de terceiros. A capacidade de pagamento tem se } \\
\text { apresentado em patamares bastante confortáveis tanto de liquidez corrente, que } \\
\text { em 2005, 2006 e 2007 apresentou respectivamente 1,92; 2,14 e 2,00; quanto de } \\
\text { liquidez seca com 1,32; 1,26 e 1,19. A empresa apresenta índices de endividamento } \\
\text { se a conta de Lucros a Distribuir aos Acionistas. A empresa aufere receitas na } \\
\text { venda de produtos, aluguel de equipamentos e licença e uso de software sendo } \\
\text { que o mercado de aluguel e equipamentos tem se mostrado bastante promissor } \\
\text { e rentável. À exceção dos recursos obtidos junto ao PJZ a empresa não possui } \\
\text { endividamento e suas fontes de investimento são exclusivamente de recursos } \\
\text { próprios, de acionistas e fornecedores. }\end{array}$ \\
\hline
\end{tabular}




\section{Continuação}

\begin{tabular}{|c|c|}
\hline Empresa & $\begin{array}{l}\text { Informações qualitativas concedidas pelas empresas relacionadas aos aspectos } \\
\text { econômico-financeiros }\end{array}$ \\
\hline MPEI - 04 & Não mencionou, pois o projeto encontra-se paralisado. \\
\hline MPEI - 05 & $\begin{array}{l}\text { Comparando } 2007 \text { com } 2008 \text { os índices econômico-financeiros da empresa } \\
\text { melhoraram. }\end{array}$ \\
\hline MPEI - 06 & $\begin{array}{l}\text { O grau de risco financeiro da empresa é baixo. A empresa apresentou um crescimento } \\
\text { de } 35 \% \text { no seu faturamento do ano de } 2008 \text { para } 2007 \text {. Neste momento, não possui } \\
\text { problemas de capacidade de pagamento ou solvência. O grau de endividamento da } \\
\text { empresa presente é de } 1,25 \text {. }\end{array}$ \\
\hline MPEI - 07 & $\begin{array}{l}\text { A empresa está equilibrada em termos de recursos, empréstimos para giro e quadro } \\
\text { de pessoal compatível, mas o risco financeiro está associado a pedidos ou clientes } \\
\text { de grande porte que a empresa possa atender, pois com volumes de pedidos } \\
\text { grandes a empresa enfrenta riscos de tomada de recursos para giro sem cobertura } \\
\text { de aval. Para esta realidade próxima, a empresa está no momento abrindo capital } \\
\text { para um fundo de investimento com } 80 \% \text { de recursos do BNDES. A atratividade } \\
\text { do fundo de investimento em participar da empresa só ocorreu por conta da } \\
\text { tecnologia gerada com o apoio do PJZ e de outros recursos de subvenção. }\end{array}$ \\
\hline MPEI - 08 & $\begin{array}{l}\text { Rentabilidade: } 2006=58,79 \% \text { e } 2008=61,28 \% \text {. Além da FINEP possuímos financiamentos } \\
\text { a curto prazo com instituições bancárias. }\end{array}$ \\
\hline MPEI - 09 & $\begin{array}{l}\text { Hoje a empresa é muito rentável em virtude da inovação tecnológica associada } \\
\text { aos seus produtos e serviços e de seu modelo de gestão de negócios. Possuímos } \\
\text { um sistema de controle de custos muito eficiente, o que permite a visualização } \\
\text { precisa das receitas, despesas, das necessidades presentes e futuras e decisões } \\
\text { de investimento. O melhor entendimento e controle desses fatores permitem } \\
\text { e favorecem a gestão financeira dos recursos disponíveis e o aumento de nossa } \\
\text { lucratividade. Além disso, os produtos desenvolvidos através do projeto financiado } \\
\text { foram comercializados e renderam receitas que passaram a fazer parte do quadro } \\
\text { positivo de rentabilidade e solvência da empresa. }\end{array}$ \\
\hline MPEI - 10 & $\begin{array}{l}\text { Tanto nos novos contratos e nos já existentes quando conseguimos agregar soluções } \\
\text { em software passamos a ter uma rentabilidade maior, pois nos diferenciamos dos } \\
\text { concorrentes. }\end{array}$ \\
\hline MPEI - 11 & $\begin{array}{l}\text { A rentabilidade da empresa de novembro de } 2007 \text { a setembro de } 2008 \text { foi bem } \\
\text { melhor do que a rentabilidade histórica. Após o período atravessamos } 11 \text { meses } \\
\text { de baixa rentabilidade. Hoje somos bem mais exigentes no cadastro de novos } \\
\text { clientes e conseguimos praticamente zerar a inadimplência. Nosso índice de } \\
\text { solvência permanece durante meses entre } 2,87 \text { e } 3,05 \text { enquanto no ano anterior ao } \\
\text { empréstimo, fechamos com } 1,95 \text {. Nossos pagamentos continuam rigidamente no dia } \\
\text { do vencimento. }\end{array}$ \\
\hline MPEI - 12 & $\begin{array}{l}\text { A empresa vem lutando contra a crise mundial que se instaurou. Os resultados } \\
\text { financeiros estão bem abaixo do que o esperado, mas olhando para o cenário das } \\
\text { demais empresas percebe-se que é normal esta queda e não pode ser vista de } \\
\text { forma alarmante. }\end{array}$ \\
\hline
\end{tabular}




\section{Continuação}

\begin{tabular}{|c|c|}
\hline Empresa & $\begin{array}{l}\text { Informações qualitativas concedidas pelas empresas relacionadas aos aspectos } \\
\text { econômico-financeiros }\end{array}$ \\
\hline MPEI - 13 & $\begin{array}{l}\text { Devido às características de agregação de valor dos produtos desenvolvidos com } \\
\text { o financiamento foi possível trabalhar com menores volumes de produção e } \\
\text { maior margem de lucro em média. A empresa continua com uma rentabilidade } \\
\text { positiva, maior do que anteriormente. O faturamento da empresa cresceu } \\
\text { consideravelmente sem que os custos crescessem proporcionalmente. Tal fato } \\
\text { possibilitou que a empresa obtivesse maiores lucros aumentando assim sua } \\
\text { capacidade de pagamento e de solvência. }\end{array}$ \\
\hline MPEI - 14 & Não respondeu. \\
\hline MPEI - 15 & $\begin{array}{l}\text { A empresa tem dificuldades constantes na gestão do capital de giro. Com o forte } \\
\text { aumento no faturamento o capital de giro ficou em descompasso. Foram realizados } \\
\text { empréstimos adicionais de bancos para ajustar o fluxo de caixa e se pagou juros. } \\
\text { Com a crise financeira mundial, muitos projetos foram postergados e houve também } \\
\text { projetos em andamento que foram suspensos, reflexo direto na receita da empresa. } \\
\text { Agora na fase atual estão sendo reativados. Houve um aumento do passivo da } \\
\text { empresa, dentro da faixa de controle. }\end{array}$ \\
\hline MPEI - 16 & $\begin{array}{l}\text { Tendo em vista a importância que o setor tecnológico possui dentro de setores } \\
\text { produtivos, em geral as empresas mostram situação de baixa liquidez e } \\
\text { rentabilidade e um aumento do endividamento, diante desse cenário a empresa } \\
\text { não se mostrou diferente, haja vista que obteve esses recursos para possibilitar } \\
\text { a conclusão desse projeto. Ao final do projeto financiado os números previstos } \\
\text { sofreram uma economia de recursos para que com a finalização do protótipo este } \\
\text { estivesse em condições de criar um novo produto. }\end{array}$ \\
\hline MPEI - 17 & $\begin{array}{l}\text { Desde o seu nascimento até hoje a empresa sempre gerou lucro e teve capacidade } \\
\text { própria de investimento. Contou em } 2002 \text { com o apoio da FINEP com o CT-INFO, } \\
\text { que ajudou a empresa na época dar um salto tecnológico e agora com o Juro } \\
\text { Zero ajudando na inovação da empresa. A empresa tem total capacidade de } \\
\text { pagamentos, tanto dos seus custos fixos e variáveis, como de investimentos e não } \\
\text { possui endividamento, exceto o próprio PJZ. }\end{array}$ \\
\hline MPEI - 18 & $\begin{array}{l}\text { A empresa utiliza com predominância capital próprio e vem apresentando em média } \\
\text { um endividamento geral de } 36 \% \text { dos seus ativos. Trabalha com um capital de giro } \\
\text { de } R \$ 2.700 \text { mil e está com rentabilidade de } 7,67 \% \text { em } 2009 \text {. Apresenta capacidade } \\
\text { de pagamento de } R \$ 2,14 \text { para cada } R \$ 1,00 \text { de dívida, no corrente, e R\$ } 1,72 \\
\text { para cada R\$ } 1,00 \text { de dívida, no geral. Todos os indicadores, principalmente a } \\
\text { tendência positiva em } 2009 \text { dos saldos de tesouraria, demonstram que a empresa } \\
\text { está totalmente solvente. }\end{array}$ \\
\hline MPEI - 19 & $\begin{array}{l}\text { Faturamento: previsão de fechamento do ano com aumento de } 45 \% \text { em relação ao } \\
\text { anterior. Lucro líquido: previsão de } 20 \text { a } 25 \% \text { da receita bruta, conforme informações } \\
\text { com base no balancete de } 30 / 11 / 2009 \text {. }\end{array}$ \\
\hline
\end{tabular}

Quadro 5 - Informações qualitativas concedidas pelas empresas relacionadas aos aspectos econômico-financeiros

Fonte: Dados da pesquisa.

Do exposto até o momento, pode-se afirmar que, tomando como base as análises realizadas na presente pesquisa, os resultados guardam consonância com os achados da tese de doutorado de Marques (2004) que investigou o impacto da 
inovação no desempenho econômico-financeiro de empresas industriais portuguesas e, de maneira geral, constatou que: (i) as empresas inovadoras apresentam um melhor desempenho econômico-financeiro do que as empresas não inovadoras; (ii) os indicadores de desempenho econômico-financeiro do primeiro ano analisado estão fortemente correlacionados com os indicadores dos anos seguintes, o que indica uma correlação elevada entre a persistência dos índices de rentabilidade e os níveis de crescimento das empresas analisadas; e (iii) os índices de rentabilidade das empresas são um importante indicador de financiamento interno para as empresas analisadas.

\section{CONSIDERAÇÕES FINAIS}

As MPEs brasileiras desempenham papel essencial ao desenvolvimento do País e para promover sua participação de forma mais competitiva na transformação dos sistemas de produção e gestão e, logo, na inovação, políticas públicas direcionadas a empreendimentos dessa natureza são indispensáveis. Nesse sentido, esta pesquisa teve como objetivo verificar o impacto do projeto inovador financiado pelo Programa Juro Zero da FINEP no desempenho econômico-financeiro das MPEls catarinenses, com o suporte da análise dos demonstrativos contábil-financeiros das respectivas empresas. Para tanto, realizou-se um estudo do tipo descritivo, por meio de um estudo de casos múltiplos, com abordagem qualitativa-quantitativa dos dados.

Nesse sentido, concluiu-se que a pesquisa permitiu verificar a ocorrência de reflexos positivos no foco de análise investigado (impacto da inovação no desempenho econômico-financeiro), especialmente por conta da melhora na liquidez e rentabilidade das empresas no período pós-financiamento, evidenciando a importância da inovação tecnológica para desenvolvimento e fortalecimento das MPEls catarinenses, obtidos por meio do Programa Juro Zero da FINEP, conforme evidenciado na pesquisa de Marques (2004). De forma mais pontual, com base na pesquisa foi possível inferir as conclusões a seguir.

No primeiro objetivo específico, os resultados do perfil das MPEls catarinenses beneficiadas pelo PJZ apontaram para os seguintes fatos: a maior parte das empresas é de pequeno porte, constituída na forma de sociedade por quotas de responsabilidade limitada, estabelecida no município de Florianópolis - polo de TI reconhecido em Santa Catarina (ABES, 2009) - com 58\% dos projetos aprovados no Estado, seguido por Joinville (20\%) e atuante no setor de software (TIC), corroborando com outros estudos empíricos (MCT, 2001). Após a classificação dos projetos inovadores em verticais, observou-se que o PJZ, além de incentivar o desenvolvimento das MPEls, também promove possibilidades de melhora de produtividade e competitividade às empresas de diversos segmentos importantes para a economia em todos os estados brasileiros por meio do apoio do Programa ao desenvolvimento de soluções inovadoras de TI.

No que diz respeito às particularidades dos projetos inovadores catarinenses financiados pelo PJZ, nota-se que o $71 \%$ dos valores financiados pelo PJZ oscilam 
entre $R \$ 450.000,01$ a $R \$ 900.000,00$, constatou-se que a rubrica de maior cobertura dos 31 projetos financiados em Santa Catarina refere-se a Despesas com Pessoal, que representa $47 \%$ do valor total financiado. Esse fato condiz com os anseios da FINEP, já que os recursos do PJZ são oriundos do Fundo de Amparo ao Trabalhador (FAT). Após a análise dos projetos constatou-se que $87 \%$ das MPEls optaram por executar o projeto no prazo máximo estabelecido pelo programa que é de 18 meses.

Quanto ao terceiro objetivo específico - identificação dos aspectos da inovação desenvolvida pelas MPEls analisadas - verificou-se que $22,73 \%$ das MPEls catarinenses efetuaram o registro de marcas e patentes do produto financiado pelo PJZ, fato este que corrobora com os achados de outras pesquisas que investigaram o registro de marcas e patentes em EBTs incubadas (FERREIRA; OLIVA; CORREA, 2009; GALLON; ENSSLIN; SILVEIRA, 2009). Além disso, constatou-se que $42,11 \%$ das MPEls analisadas firmaram parcerias e/ou cooperações com instituições de pesquisa para a consecução do projeto inovador financiado pelo PJZ, tal achado diverge do estudo desenvolvido por Miziara e Carvalho (2008) que perceberam que as atividades de parceria e cooperação dessa natureza são pouco freqüentes nas EBTs, sendo predominantemente informal.

Por fim, quanto à análise do desempenho econômico-financeiro das MPEls catarinenses com a implementação do projeto inovador, destaca-se que: (i) a maioria das empresas financiadas obtiveram aumentos em suas receitas e que, em média, o faturamento das MPEls aumentou 49,13\% após o financiamento, observou-se, também, o crescimento da comercialização dos produtos e serviços das empresas pesquisadas principalmente no mercado externo, fato este que evidencia a importância do financiamento de inovação tecnológica para as MPEls; (ii) com relação à analise dos índices médios de liquidez, endividamento e rentabilidade, em linhas gerais, constatou-se uma melhora nos índices de liquidez e rentabilidade, observou-se, também, que o período pós-financiamento coincide em várias empresas com o período de comercialização dos produtos, evidenciando desta forma que a comercialização dos produtos e/ou serviços inovadores, oriundos do PJZ, tem relação com a evolução do desenvolvimento das MPEls analisadas; e, (iii) com relação aos índices de endividamento médio das MPEls percebeu-se um aumento do período do pós-financiamento em relação ao exercício da concessão do financiamento, fato este explicado pela contabilização do financiamento do PJZ obtido pela empresa.

Do exposto, tomando como base as análises realizadas da pesquisa, constatouse a importância do PJZ para as MPEls beneficiadas e observou-se que este Programa, como política de inovação, está conseguindo alcançar seus objetivos: (i) apoiar os projetos desenvolvidos por MPEls, que representem uma inovação em seu setor de atuação; e, (ii) estimular o desenvolvimento das MPEls brasileiras viabilizando o acesso ao crédito.

Por fim, cabe evidenciar que os impactos econômico-financeiros constatados na pesquisa podem não terem sido gerados especificamente em função do projeto inovador financiado pelo PJZ, mas terem sido motivados por fatores alheios ao projeto. Entretanto, com base na exposição das empresas, em linhas gerais, a inovação financiada influenciou positivamente para a melhoria dos resultados sociais e econômico-financeiros nas MPEls, fato já constatado em outras pesquisas 
empíricas (MARQUES, 2004) e que pode servir como direcionamento para despertar cada vez mais o interesse pelo apoio à inovação por parte da administração pública, possibilitando a abertura de oportunidades para desenvolvimento de projetos nacionais de inovação.

Sugere-se para futuras pesquisas a replicação da pesquisa com as MPEls sediadas nos estados do Paraná, Bahia, Minas Gerais, Pernambuco, e um estudo comparativo com outras MPEls que não receberam aporte financeiro do PJZ, com vistas a investigar semelhanças e discrepâncias entre os reflexos do PJZ da FINEP no que diz respeito ao desempenho econômico-financeiro das MPEls.

\section{REFERÊNCIAS}

ABES - Associação Brasileira das Empresas de Software. Disponível em: < $\underline{\text { http: //www.abes. }}$ org.br>. Acesso em: 21 out. 2009.

ALVIM, P. C. R. C. O papel da informação no processo de capacitação tecnológica das micro e pequenas empresas. Ciência da Informação, Brasília, v. 27, n. 1, p. 28-35, jan./abr. 1998.

ASSAF NETO, A. Estrutura e análise de balanços: um enfoque econômico-financeiro. 9. ed. São Paulo: Atlas, 2010.

BAÊTA, A. M. C.; BORGES, C. V.; TREMBLAY, D. G. Empreendedorismo nas incubadoras: reflexões sobre tendências atuais. Comportamento Organizacional e Gestão, v. 12, 1, p. 7-18, 2006.

BARBETTA, P. A. Estatística aplicada às ciências sociais. 4. ed. Florianópolis: Ed. da UFSC, 2001.

BRASIL. Novo Código Civil. Lei n. 10.406, de 10 de janeiro de 2002. Institui o Novo Código Civil. Disponível em: <www.planalto.gov.br>. Acesso em: 5 ago. 2009.

BRASIL. Portaria MDIC ${ }^{\circ} 176$, de $1^{\circ}$ de outubro de 2002. Ministério do Desenvolvimento, Indústria eComércioExterior. Disponível em:< http://www.desenvolvimento.gov.br/ arquivo/legislacao/

portarias/ministeriais/pt176de2002Camex.pdf >. Acesso em: 20 set. 2009.

CORDER, S.; SALLES-FILHO, S. Aspectos conceituais do financiamento à inovação. Revista Brasileira de Inovação, Rio de Janeiro, v. 5, 1, p. 33-76, jan./jun. 2006.

FERREIRA, A. A.; OLIVA, F. L.; CORREA, S. A. M. Formação de redes para o desenvolvimento tecnológico: Uma experiência com empresas de base tecnológica. In: 5ème Colloque de l'IFBAE. Anais... Grenoble, Mai. 2009. CD-ROM.

FINEP - Financiadora de Estudos e Projetos. Disponível em: <http://www.finep.gov.br>. Acesso em: 21 set. 2009.

GALLON, A. V.; ENSSLIN, S. R. Infraestrutura operacional em empresas de base tecnológica 
(EBTs) incubadas e sua importância para a performance organizacional. In: CONTECSI, 5., 2008, São Paulo. Anais... São Paulo: FEA/USP, 2008. CD-ROM.

GALLON, A. V.; ENSSLIN, S. R.; SILVEIRA, A. Rede de relacionamentos em pequenas empresas de base tecnológica (EBTS) incubadas: um estudo da sua importância para o desempenho organizacional na percepção dos empreendedores. Journal of Information Systems and Technology Management, v. 6, 3, p. 551-572, set./dez. 2009.

GIL, A. C. Métodos e técnicas de pesquisa social. São Paulo: Atlas, 1999.

GITMAN, L. J. Princípios de administração financeira. 7. ed. São Paulo: Harbra, 2002.

IUDíCIBUS, S. Análise de balanços: análise da liquidez e do endividamento; análise do giro; rentabilidade e alavancagem financeira. 10. ed. São Paulo: Atlas, 2009.

MARQUES, C. S. E. O impacto da inovação no desempenho económico-financeiro das empresas industriais portuguesas. $312 \mathrm{f}$. Tese (Doutorado em Gestão). Universidade de Trás-os-Montes e Alto Douro, Vila Real, 2004.

MARTINEZ, J. B. El proceso de creación de EIBTs: ciclo vital e apoyos al desarrollo y crecimiento. Madrid: Creara Fundación San Telmo, ANCES, 2003.

MATARAZZO, D. C. Análise financeira de balanços: abordagem básica e gerencial. 6. ed. São Paulo: Atlas, 2007.

MIZIARA, G. N.; CARVALHO, M. M. Fatores críticos de sucesso em incubadoras de empresas de software. Revista Produção On Line, v. 8, n. 3, 2008. p. 1-20.

MOROZINI, J. F. Análise econômico-financeira de sociedades anônimas em processo de concordata na cidade de Curitiba/PR. 171 f. Dissertação (Mestrado em Ciências Contábeis). Universidade Regional de Blumenau. Blumenau, 2005.

OECD - Organization for Economic Cooperation and Development. Disponível em: <www. oecd.org>. Acesso em: 10 nov. 2009.

PASCOTTO, H.; MACHADO, H. V. Dificuldades de pequenas empresas do setor de serviços securitários nos primeiros anos de vida. Revista Eletrônica de Gestão Organizacional, v. 4, 1, p. 52-68, jan./abr. 2006.

RICHARDSON, R. J. Pesquisa social: métodos e técnicas. São Paulo: Atlas, 1999.

SEBRAE - Serviço Brasileiro de Apoio às Micro e Pequenas Empresas. Fatores condicionantes e taxa de mortalidade de empresas no Brasil. Relatório de Pesquisa. Brasília, agosto 2004. Disponível em: <http://www.portal.sebrae.com.br>. Acesso em: 12 dez. 2009.

SILVA, J. P. Gestão e análise de risco de crédito. 6. ed. São Paulo: Atlas, 2008.

SILVA, J. P. Análise financeira das empresas. 10. ed. São Paulo: Atlas, 2010. 


\section{ENDEREÇOS DOS AUTORES:}

\section{Alessandra Vasconcelos Gallon}

Universidade Federal do Ceará

Faculdade de Economia Adm., Atuária, Contab. e Secretariado e Executivo Av. da Universidade 2431 - Benfica

Fortaleza, CE - Brasil

$60020-180$

\section{Diane Rossi Reina}

Universidade Federal de Santa Catarina

Centro Sócio Econômico

Campus Universitário - Trindade

Caixa-Postal: 476

Florianopolis SC - Brasil

88040-900

\section{Sandra Rolim Ensslin}

Universidade Federal de Santa Catarina

Centro Sócio-Econômico, Departamento de Ciências Contábeis,CCN/CSE/UFSC

Campus Universitário - Caixa Postal 476

Florianopolis, SC - Brasil

88010-970 